\title{
Temperature behaviour of fundamental absorption edge in superionic $\mathrm{Ag}_{6} \mathrm{PS}_{5} \mathrm{I}$ crystals
}

\author{
${ }^{1}$ Studenyak I. P., ${ }^{1}$ Pop M. M., ${ }^{1}$ Shender I. O., ${ }^{1}$ Pogodin A. I. and ${ }^{2}$ Kranjcec M. \\ ${ }^{1}$ Uzhhorod National University, 46 Pidhirna Street, 88000 Uzhhorod, Ukraine. \\ studenyak@dr.com \\ ${ }^{2}$ North University, 33 J. Križanića Street, 42000 Varazdin, Croatia mladen. \\ kranjcec@yahoo.com
}

Received: 27.09 .2021

\begin{abstract}
Ag}_{6} \mathrm{PS}_{5} \mathrm{I}$ single crystals are grown from solution-melt by means of a vertical zone crystallization method. Dispersion of the refractive index of $\mathrm{Ag}_{6} \mathrm{PS}_{5} \mathrm{I}$ measured with a spectral ellipsometry technique is described by a known WempleDiDomenico relation. The fundamental absorption edge for the $\operatorname{Ag}_{6} \mathrm{PS}_{5} \mathrm{I}$ crystals is studied in the temperature range $77-300 \mathrm{~K}$. The temperature dependences of the optical pseudogap and the Urbach energy are analyzed in the framework of Einstein model. The parameters of electron-phonon interaction, which results in the Urbach behaviour of the fundamental absorption edge, are determined. The influence of temperature and structural disorderings on the optical absorption in $\operatorname{Ag}_{6} \mathrm{PS}_{5} \mathrm{I}$ is studied.
\end{abstract}

Keywords: superionic conductors, crystal growth, spectral ellipsometry, fundamental absorption edge, structural disorder

UDC: 535.343

\section{Introduction}

Development of secondary energy sources leads to creation of new functional materials with better operational characteristics $[1,2]$. One of the promising directions is represented by all-solid-state batteries with inorganic superionic conductors as electrolytes [1-3]. The main requirement for the appropriate materials is their high ionic conductivity, which is provided by mobile ions, large number of possible crystallographic positions and their partial occupancy [4]. In particular, the above materials include a number of compounds with argyrodite structure [5-7]. They contain two types of cations in their composition: a multi-charged cation forming a rigid anionic frame with an anion and a single-charged cation with different coordination and occupancy positions [5-7]. Phosphorus-containing argyrodites $\mathrm{Me}_{6} \mathrm{PS}_{5} \mathrm{X}\left(\mathrm{Me}=\mathrm{Cu}^{+}, \mathrm{Ag}^{+}, \mathrm{Li}^{+}\right.$, and $\left.\mathrm{X}=\mathrm{Cl}, \mathrm{Br}, \mathrm{I}\right)$ are now the most investigated. Structural, electrical and optical properties of these materials prepared in the form of single- and poly-crystals, composites, ceramics and thin films have been earlier studied in Refs. [8-15].

It should be noted that high ionic conductivity affects significantly the optical processes in superionic conductors. Moreover, it is known that structural disordering in these materials has a dynamic nature due to a presence of mobile ions, which is reflected in additional 'blurring' of fundamental absorption edge [16].

$\mathrm{Up}$ to date, the optical properties of copper-conducting argyrodites $\mathrm{Cu}_{6} \mathrm{PS}_{5} \mathrm{X}$ have been studied in the most detail. At the same time, there is almost no information about the processes of optical absorption in silver-containing superionic conductors with argyrodite structure, $\mathrm{Ag}_{6} \mathrm{PS}_{5} \mathrm{X}$. Although the study [5] informs that $\mathrm{Ag}_{6} \mathrm{PS}_{5} \mathrm{I}$ belongs to the cubic system (with the space group 
$F \overline{4} 3 m$ and the lattice parameter $a=10.474 \AA$ ), its crystal structure has not been described. It has been shown, however, that the electrical conductivity of polycrystalline $\mathrm{Ag}_{6} \mathrm{PS}_{5} \mathrm{I}$ samples is equal to $1.2 \times 10^{-4} \mathrm{~S} / \mathrm{cm}$ at $300 \mathrm{~K}$ and the corresponding activation energy amounts to $0.24 \mathrm{eV}$. Higher electrical conductivity $\left(7.4 \times 10^{-4} \mathrm{~S} / \mathrm{cm}\right.$ at $\left.300 \mathrm{~K}\right)$ and lower activation energy $(0.22 \mathrm{eV})$ for the poly-crystalline $\mathrm{Ag}_{6} \mathrm{PS}_{5} \mathrm{I}$ samples have been reported in Ref. [16]. Finally, the electrical properties of the composites based on $\left(\mathrm{Cu}_{1-\mathrm{x}} \mathrm{Ag}_{\mathrm{x}}\right)_{6} \mathrm{PS}_{5} \mathrm{I}$ solid solutions have been investigated in Ref. [17].

In the present study we report the refractive-index dispersion and the temperature behaviour of fundamental absorption edge in the superionic conductor $\mathrm{Ag}_{6} \mathrm{PS}_{5} \mathrm{I}$. Our other aims are roles of electron-phonon interaction (EPI) and crystal-lattice ordering-disordering in the formation of absorption edge.

\section{Experimental}

$\mathrm{Ag}_{6} \mathrm{PS}_{5} \mathrm{I}$ compound was synthesised using such simple substances as silver (99.995\%), phosphorus (99.999\%), sulphur (99.999\%), and pre-synthesized binary silver (I) iodide additionally purified using a directional crystallization method. A regime of synthesis of $\mathrm{Ag}_{6} \mathrm{PS}_{5} \mathrm{I}$ included a stepped heating up to $723 \mathrm{~K}$ at the rate close to $100 \mathrm{~K} / \mathrm{h}$ (ageing during $48 \mathrm{~h}$ ), a further increase in temperature up to $1100 \mathrm{~K}$ at the rate $50 \mathrm{~K} / \mathrm{h}$, and ageing at this temperature for $24 \mathrm{~h}$. Cooling was performed in an oven-off mode.

The growth of $\mathrm{Ag}_{6} \mathrm{PS}_{5} \mathrm{I}$ single crystals was carried out with a method of vertical-zone crystallization from a solution-melt in a two-zone tubular resistance furnace (with the melt-zone temperature $1075 \mathrm{~K}$ and the annealing zone $680 \mathrm{~K}$ ), using a specially configured silica container. To homogenize the melt, a $24 \mathrm{~h}$-long ampoule ageing was carried out in the melt zone. The growth of the single crystal included formation of a seed in a lower conical part of the container by applying a method of recrystallization in the course of $24 \mathrm{~h}$ and build-up of the crystal on the seed thus formed. The rate of crystallization-front movement was equal to $0.4 \ldots 0.5 \mathrm{~mm} / \mathrm{h}$, the annealing temperature $680 \mathrm{~K}$ (for $72 \mathrm{~h}$ ), and the rate of cooling down to the room temperature $5 \mathrm{~K} / \mathrm{h}$. As a result, $\mathrm{Ag}_{6} \mathrm{PS}_{5} \mathrm{I}$ single crystals of dark red colour with a metallic luster were obtained, with the lengths $30-40 \mathrm{~mm}$ and the diameters close to $12 \mathrm{~mm}$.

A spectroscopic ellipsometer Horiba Smart SE was employed to measure the optical constants of $\mathrm{Ag}_{6} \mathrm{PS}_{5} \mathrm{I}$. Measurements of the ellipsometric angles $\Psi$ and $\Delta$ were carried out in the spectral region from 440 to $1000 \mathrm{~nm}$ at the incidence angle $\varphi_{0}=70^{\circ}$. The main ellipsometric equation was solved for every set of the $\varphi_{0}, \Psi$ and $\Delta$ parameters [18].

Spectral dependences of the absorption coefficient $\alpha$ were studied in the temperature range 77-300 K. The samples for the optical transmittance and reflectance measurements were oriented at the room temperature while being in the cubic phase. The linear absorption coefficient $\alpha$ as a function of transmittance $T_{t r}$ and surface reflectance $R$ was calculated using a well-known formula that takes internal multiple reflections into account:

$$
\alpha=\frac{1}{d} \ln \left\{\frac{(1-R)^{2}}{2 T_{t r}}+\sqrt{\left[\frac{(1-R)^{2}}{2 T_{t r}}\right]^{2}+R^{2}},\right.
$$

with $d$ denoting the thickness of a plane-parallel sample. The experimental setup and technique have been described elsewhere (see, e.g., Ref. [19]). The relative error in determination of the absorption coefficient $\Delta \alpha / \alpha$ did not exceed $10 \%$ in the interval defined as $0.3 \leq \alpha d \leq 3$ [19].

Ukr. J. Phys. Opt. 2021, Volume 22, Issue 4 


\section{Results and discussion}

Fig. 1 shows the spectral dependence of the refractive index of $\operatorname{Ag}_{6} \mathrm{PS}_{5} \mathrm{I}$ measured with the spectral ellipsometry technique. Inside the transparency region, the refractive index increases when approaching the region of absorption edge. An anomalous dispersion is seen in the region where the extinction coefficient increases. This anomaly corresponds to the band-to-band optical transitions and its spectral position is related to the energy-gap value. The dispersion of the refractive index in the transparency region can be described by a Wemple-DiDomenico relation [20]:

$$
n^{2}(E)-1=\frac{E_{d}^{W D} \times E_{0}^{W D}}{\left(E_{0}^{W D}\right)^{2}-E^{2}},
$$

where $E_{0}{ }^{W D}$ is the single-oscillator energy and $E_{\mathrm{d}}{ }^{\mathrm{WD}}$ the dispersion energy characterizing the average strength of the inter-band optical transitions. It is associated with changes in the structural ordering of a material. The parameters of the Wemple-DiDomenico model for the $\mathrm{Ag}_{6} \mathrm{PS}_{5} \mathrm{I}$ single crystals amount to $E_{0}{ }^{\mathrm{WD}}=5.17 \mathrm{eV}$ and $E_{\mathrm{d}}{ }^{\mathrm{WD}}=26.49 \mathrm{eV}$. We have also calculated the model parameters associated with the static refractive index $n_{0}=\left[1+\left(E_{\mathrm{d}} / E_{0}\right)\right]^{1 / 2}$ and the ionicity $f_{\mathrm{i}}=\left(E_{0} / E_{\mathrm{d}}\right)^{1 / 2}[21]$. They are equal to 2.47 and 0.44 , respectively.

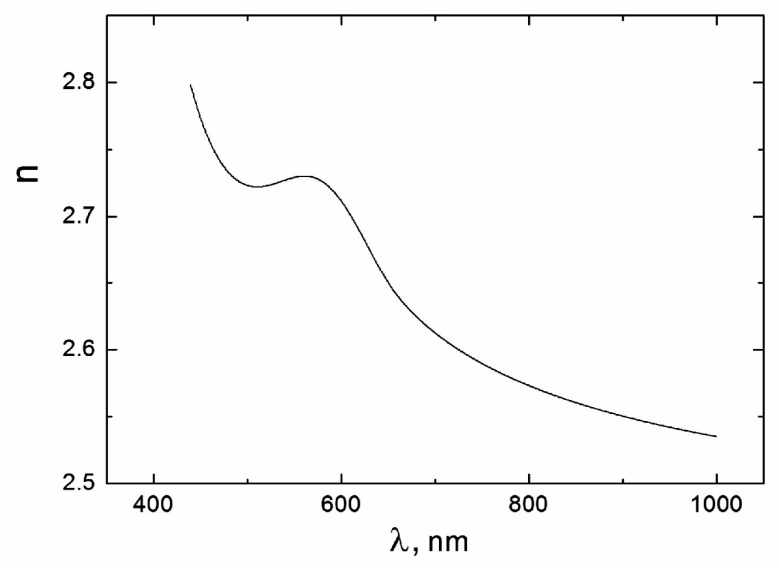

Fig. 1. Dispersion of refractive index for $\mathrm{Ag}_{6} \mathrm{PS}_{5}$ m measured at the room temperature.

Our temperature studies of the fundamental absorption edge for the $\mathrm{Ag}_{6} \mathrm{PS}_{5} \mathrm{I}$ crystals have testified that its shape is exponential and follows the Urbach rule [22]:

$$
\alpha(h v, T)=\alpha_{o} \exp \left[\frac{\sigma\left(h v-E_{0}\right)}{k T}\right]=\alpha_{o} \exp \left[\frac{h v-E_{0}}{E_{U}(T)}\right] .
$$

Here $E_{U}$ denotes the Urbach energy, $\sigma$ the absorption-edge steepness parameter, $\alpha_{0}$ and $E_{0}$ are the coordinates of convergence-point of the Urbach bundle, $k$ is the Boltzmann constant, $T$ the temperature, and $h v$ the photon energy. Fig. 2 presents the spectral dependences of the absorption coefficient measured at different temperatures for the $\mathrm{Ag}_{6} \mathrm{PS}_{5} \mathrm{I}$ crystals. The coordinates $\alpha_{0}$ and $E_{0}$ of the point where the Urbach bundle converges for $\mathrm{Ag}_{6} \mathrm{PS}_{5} \mathrm{I}$ and its copper-containing counterpart $\mathrm{Cu}_{6} \mathrm{PS}_{5} \mathrm{I}$ are compared in Table 1 .

The exponential shape of the long-wavelength part of the absorption edge is usually linked with the EPI [23]. In the whole temperature interval under test, the temperature dependences of the steepness parameter $\sigma$ are well described with the Mahr relation [23] 


$$
\sigma(T)=\sigma_{0}\left(\frac{2 k T}{\hbar \omega_{p}}\right) \tanh \left(\frac{\hbar \omega_{p}}{2 k T}\right),
$$

where $\hbar \omega_{p}$ is the effective average phonon energy in a single-oscillator model describing the EPI [23]. An example of these dependences is presented in the insert of Fig. 1. Note that $\sigma_{0}$ is a constant independent of temperature and related to the EPI constant $g$ via the relation $\sigma_{0}=2 / 3 g$. It is worthwhile that we obtain the value $\sigma_{0}<1$, which indicates a strong enough EPI in $\operatorname{Ag}_{6} \mathrm{PS}_{5} \mathrm{I}$ [24]. The effective phonon energy $\hbar \omega_{p}$ and the $\sigma_{0}$ parameter are gathered in Table 1 . One can see that $\sigma_{0}$ decreases more than three times when compared to the same parameter of $\mathrm{Cu}_{6} \mathrm{PS}_{5} \mathrm{I}$ crystals, thus indicating a significant increase in the EPI occurring due to substitution of $\mathrm{Cu}$ with $\mathrm{Ag}$ atoms. The effective phonon energy increases by $23 \%$ when passing from $\mathrm{Cu}_{6} \mathrm{PS}_{5} \mathrm{I}$ to $\mathrm{Ag}_{6} \mathrm{PS}_{5} \mathrm{I}$.

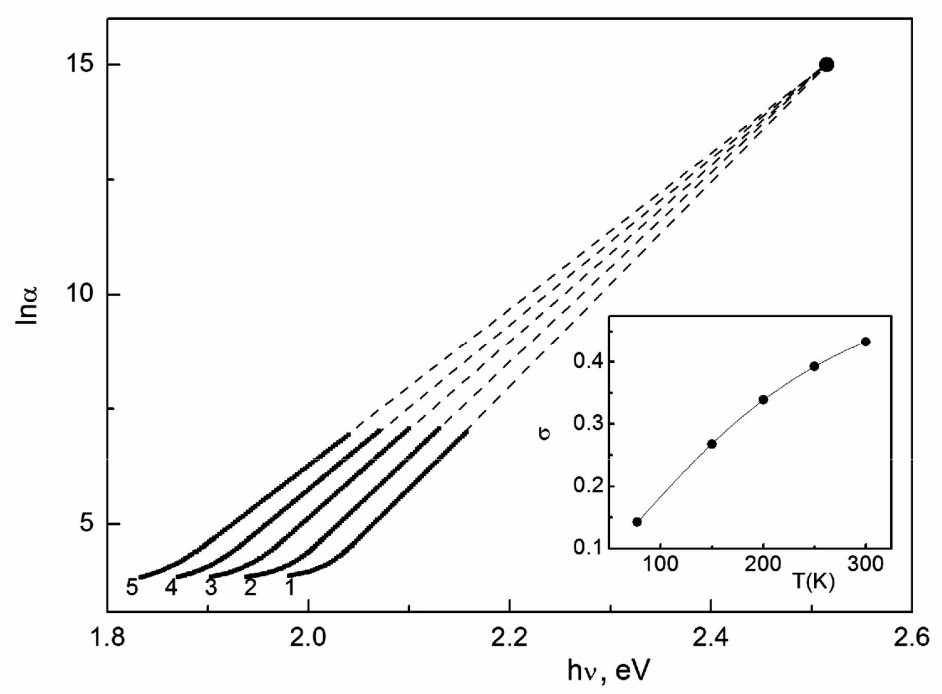

Fig. 2. Spectral dependences of fundamental absorption edge for $\mathrm{Ag}_{6} \mathrm{PS}_{5} \mathrm{I}$ measured at different temperatures: $1-77,2-150,3-200,4-250$ and $5-300 \mathrm{~K}$. Insert shows temperature dependence of the steepness parameter $\sigma$.

Table 1. Parameters of fundamental absorption edge and EPI calculated for $\mathrm{Cu}_{6} \mathrm{PS}_{5} \mathrm{I}$ [19] and $\mathrm{Ag}_{6} \mathrm{PS}_{5} \mathrm{I}$ single crystals.

\begin{tabular}{lcc} 
Single crystal & $\mathbf{C u}_{\mathbf{6}} \mathbf{P S}_{\mathbf{5}} \mathbf{I}$ & $\mathbf{A g}_{\mathbf{6}} \mathbf{P S}_{\mathbf{5}} \mathbf{I}$ \\
\hline$\alpha_{0}, \mathrm{~cm}^{-1}$ & $2.96 \times 10^{6}$ & $3.44 \times 10^{6}$ \\
$E_{0}, \mathrm{eV}$ & 2.230 & 2.515 \\
$E_{g}^{*}, \mathrm{eV}$ & 2.079 & 2.030 \\
$E_{U}, \mathrm{meV}$ & 19.3 & 59.7 \\
$\sigma_{0}$ & 1.55 & 0.58 \\
$\hbar \omega_{p}, \mathrm{meV}$ & 32.0 & 54.5 \\
$\theta_{\mathrm{E}}, \mathrm{K}$ & 371 & 633 \\
$\left(E_{\mathrm{u}}\right)_{0}, \mathrm{meV}$ & 9.6 & 46.7 \\
$\left(E_{\mathrm{u}}\right)_{1}, \mathrm{meV}$ & 23.2 & 94.5 \\
$E_{g}^{*}(0), \mathrm{eV}$ & 2.152 & 2.138 \\
$S_{g}^{*}$ & 5.6 & 14.5
\end{tabular}


Among numerous theoretical treatments of the Urbach rule, a Sumi-Toyozava model of selftrapped exciton and a Dow-Redfield microelectric-field theory involving an internal Franz-Keldysh effect $[25,26]$ are cited the most often. Issuing from our results, one can see that the EPI mechanism in the $\mathrm{Ag}_{6} \mathrm{PS}_{5} \mathrm{I}$ crystals is well explained by the Dow-Redfield theory. According to the latter, the resulting exponential absorption edge is related to the interaction of exciton (electron) with microelectric fields generated by LO phonons [26]. To further check whether the Dow-Redfield theory could describe well the EPI in $\mathrm{Ag}_{6} \mathrm{PS}_{5} \mathrm{I}$, we have applied the procedure suggested in Ref. [27], where the influence of external electric field $F_{e}$ causing the internal Franz-Keldysh effect is replaced by the root-mean square value of the phonon-induced internal electric field $F_{p}$. This approach leads to the expression

$$
E_{g}^{*} \tanh \left(\frac{\hbar \omega_{p}}{2 k T}\right)=E_{g}^{*}(0)-E_{0}\left[1-\tanh \left(\frac{\hbar \omega_{p}}{2 k T}\right)\right],
$$

where $E_{g}^{*}(0)$ is the optical pseudogap taken at the zero temperature. The linear relationship $E_{g}^{*} \tanh \left(\hbar \omega_{p} / 2 k T\right)$ vs. $\left[1-\tanh \left(\hbar \omega_{p} / 2 k T\right)\right]$ depicted in Fig. 3 supports qualitative agreement between the Dow-Redfield theory and the absorption processes taking place in $\mathrm{Ag}_{6} \mathrm{PS}_{5} \mathrm{I}$.

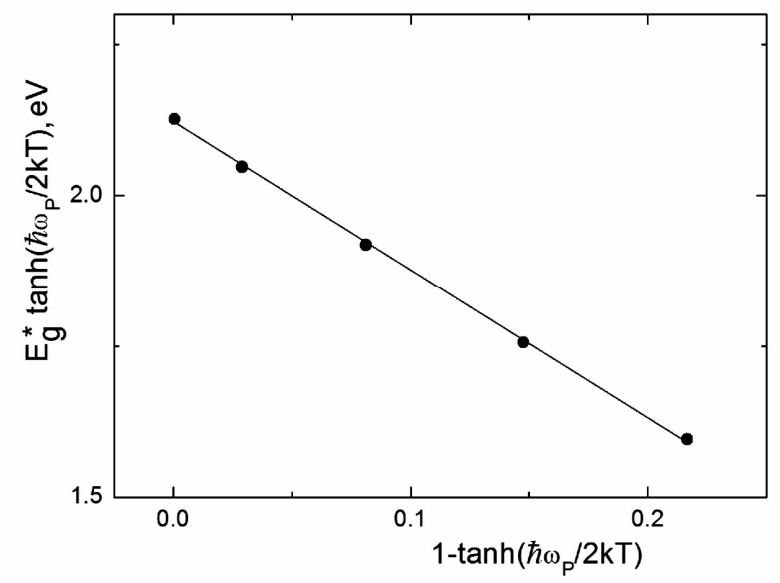

Fig. 3. Linear relationship $E_{g}^{*} \tanh \left(\hbar \omega_{p} / 2 k T\right)$ vs. $\left[1-\tanh \left(\hbar \omega_{p} / 2 k T\right)\right\rfloor$ as calculated for $\mathrm{Ag}_{6} \mathrm{PS}_{5} \mathrm{I}$ single crystals.

Following from the analysis of Urbach absorption edge, one can determine the optical pseudogap $E_{g}^{*}$ (i.e., the energy position of the absorption edge taken at a fixed value of absorption coefficient, $\alpha=10^{3} \mathrm{~cm}^{-1}$ ) and the Urbach energy $E_{U}$ (i.e., the energy width of the exponential absorption edge). The temperature dependences of the $E_{g}^{*}$ and $E_{U}$ parameters for the $\operatorname{Ag}_{6} \mathrm{PS}_{5} \mathrm{I}$ crystals are presented in Fig. 4. Note that the temperature behaviour of $E_{g}^{*}$ parameter in Fig. 4, which is due to the EPI, can be described by the Einstein model through the relation [28]

$$
E_{g}^{*}(T)=E_{g}^{*}(0)-S_{g}^{*} k \theta_{E}\left[\frac{1}{\exp \left(\theta_{E} / T\right)-1}\right],
$$

where $E_{g}^{*}(0)$ and $S_{g}^{*}$ are respectively the optical pseudogap at $0 \mathrm{~K}$ and a dimensionless constant and $\theta_{E}$ implies the Einstein temperature corresponding to the average frequency of phonon excitati- 
ons of a system of non-coupled oscillators. Our calculations have demonstrated that the experimental $E_{g}^{*}$ values are satisfactorily described by Eq. (6). The $E_{g}^{*}(0), S_{g}^{*}$ and $\theta_{E}$ parameters obtained for $\mathrm{Ag}_{6} \mathrm{PS}_{5} \mathrm{I}$ are given in Table 1 , while the temperature dependence of the optical pseudogap $E_{g}^{*}$ calculated from Eq. (6) is shown in Fig. 4 as a solid line. In addition, Table 1 displays the corresponding optical parameters for the $\mathrm{Cu}_{6} \mathrm{PS}_{5} \mathrm{I}$ crystals. It is important that transition from $\mathrm{Cu}_{6} \mathrm{PS}_{5} \mathrm{I}$ to $\mathrm{Ag}_{6} \mathrm{PS}_{5} \mathrm{I}$ decreases slightly the optical pseudogap and increases the Urbach energy more than three times. This indicates a significant increase in disordering of crystal lattice that happens when $\mathrm{Cu}$ atoms are substituted by Ag ones.

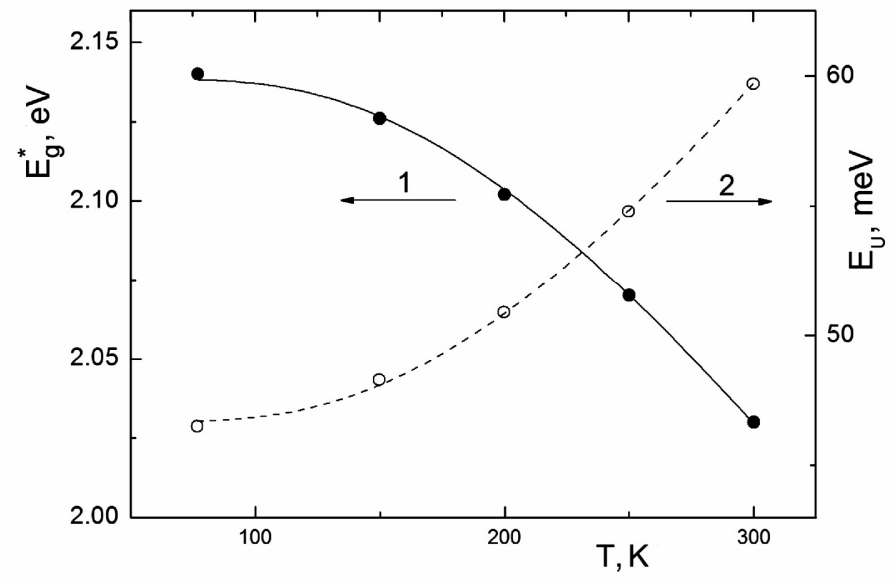

Fig. 4. Temperature dependences of optical pseudogap $E_{g}^{*}$ (1) and Urbach energy $E_{U}$ (2) for $\mathrm{Ag}_{6} \mathrm{PS}_{5} \mathrm{l}$ : circles correspond to experiment and curves to calculation

It is well known that the Urbach energy $E_{U}$ in the Einstein model is described as [29]

$$
\left(E_{U}\right)=\left(E_{U}\right)_{0}+\left(E_{U}\right)_{1}\left[\frac{1}{\exp \left(\theta_{E} / T\right)-1}\right],
$$

where $\left(E_{U}\right)_{0}$ and $\left(E_{U}\right)_{1}$ are constants. The $\left(E_{U}\right)_{0}$ and $\left(E_{U}\right)_{1}$ values obtained when fitting the experimental temperature dependences of $E_{U}$ for $\mathrm{Ag}_{6} \mathrm{PS}_{5} \mathrm{I}$ with Eq. (7) are listed in Table 1. Finally, the temperature dependence of the Urbach energy $E_{U}$ for $\mathrm{Ag}_{6} \mathrm{PS}_{5} \mathrm{I}$ is shown in Fig. 4 as a dashed line.

It has been shown in Ref. [30] that both the temperature-related disordering and the structural disordering affect the shape of Urbach absorption edge, so that the Urbach energy $E_{U}$ can be described as

$$
E_{U}=\left(E_{U}\right)_{T}+\left(E_{U}\right)_{X}=\left(E_{U}\right)_{T}+\left(E_{U}\right)_{X, \text { stat }}+\left(E_{U}\right)_{X, d y n},
$$

where $\left(E_{U}\right)_{T}$ and $\left(E_{U}\right)_{X}$ are respectively the contributions of temperature-related and structural disorderings into $E_{U}$, and $\left(E_{U}\right)_{X, \text { stat }}$ and $\left(E_{U}\right)_{X, d y n}$ respectively the contributions of the static structural disordering and the dynamic structural disordering into $\left(E_{U}\right)_{X}$. The static structural disordering $\left(E_{U}\right)_{X \text {,stat }}$ in the $\mathrm{Ag}_{6} \mathrm{PS}_{5} \mathrm{I}$ crystals is known to be caused by structural imperfection occurring due to high concentration of disordered copper vacancies. On the other hand, the dynamic structural disordering $\left(E_{U}\right)_{X, d y n}$ is related to intense motion of mobile copper ions participating 
in ion transport, which is responsible for the ionic conductivity [16]. Notice also that the first term in the r.-h. s. of Eq. (7) represents the static structural disordering and the second term is associated with the temperature-related types of disordering: a temperature disordering due to thermal lattice vibrations and a dynamic structural disordering due to a presence of mobile ions in superionic conductors.

Finally, we have evaluated the contributions of the static structural disordering and the temperature-related types of disordering into the Urbach energy $E_{U}$ for $\mathrm{Ag}_{6} \mathrm{PS}_{5} \mathrm{I}$. It has been demonstrated that the absolute contribution of the static structural disordering increases when $\mathrm{Cu}$ atoms are substituted by $\mathrm{Ag}$ ones (see Table 1). Hence, the contribution of the static structural disorder into the Urbach energy in $\mathrm{Cu}_{6} \mathrm{PS}_{5} \mathrm{I}$ constitutes $49.7 \%$, while it is $64.4 \%$ in $\mathrm{Ag}_{6} \mathrm{PS}_{5} \mathrm{I}$.

\section{Conclusions}

The optical properties of the $\mathrm{Ag}_{6} \mathrm{PS}_{5} \mathrm{I}$ single crystals grown from solution-melt by means of the vertical-zone crystallization method are studied using the methods of spectral ellipsometry and absorption-edge spectroscopy. It is shown that dispersion of the refractive index is well described by the Wemple-DiDomenico model. The optical absorption edge in $\mathrm{Ag}_{6} \mathrm{PS}_{5} \mathrm{I}$ has the exponential shape and follows the Urbach rule. The temperature behaviour of the Urbach absorption edge is determined by the EPI which is strong enough in the $\mathrm{Ag}_{6} \mathrm{PS}_{5} \mathrm{I}$ crystals.

The temperature dependences of the optical pseudogap $E_{g}^{*}$ and the Urbach energy $E_{U}$ are obtained experimentally. They are described well in the framework of the Einstein model. Concerning comparison with the $\mathrm{Cu}_{6} \mathrm{PS}_{5} \mathrm{I}$ counterpart, the following distinctive phenomena are observed in the $\mathrm{Ag}_{6} \mathrm{PS}_{5} \mathrm{I}$ crystals: (i) absence of the anomalies associated with phase transitions on the temperature dependence of the absorption edge, (ii) absence of any exciton bands on the spectral dependences, (iii) a shift of the absorption edge towards the long-wavelength region, (iv) significant 'smearing' of the absorption edge due to increase in the contribution of static structural disordering into the Urbach energy, and (v) increase in the EPI and the effective phonon energy.

\section{References}

1. Ohno S, Banik A, Dewald G F, Kraft M A, Krauskopf T, Minafra N, Till P, Weiss M and Zeier W G, 2020. Materials design of ionic conductors for solid state batteries. Progr. Energy. 2: 022001.

2. Grey C P and Hall D S, 2020. Prospects for lithium-ion batteries and beyond - a 2030 vision. Nature Commun. 11: 6279.

3. Sun Y-K, 2020. Promising all-solid-state batteries for future electric vehicles. ACS Energy Lett. 5: 3221-3223.

4. He X, Zhu Y and Mo Y, 2017. Origin of fast ion diffusion in super-ionic conductors. Nature Commun. 8: 15893.

5. Kuhs W F, Nitsche R and Scheunemann K, 1979. The argyrodites - a new family of tetrahedrally close-packed structures. Mat. Res. Bull. 14: 241-248.

6. Nilges T and Pfitzner A, 2005. A structural differentiation of quaternary copper argyrodites: Structure - property relations of high temperature ion conductors. Z. Kristallogr. 220: 281-294.

7. Zhou L, Assoud A, Zhang Q, Wu X and Nazar L F, 2019. New Family of argyrodite thioantimonate lithium superionic conductors. J. Amer. Chem. Soc. 141: 19002-19013.

8. Studenyak I P, Stefanovich V O, Kranjcec M, Desnica D I, Azhnyuk Yu M, Kovacs Gy Sh and Panko V V, 1997. Raman scattering studies of $\mathrm{Cu}_{6} \mathrm{PS}_{5} \mathrm{Hal}(\mathrm{Hal}=\mathrm{Cl}, \mathrm{Br}$, I) fast-ion conductors. Solid State Ionics. 95: 221-225. 
9. Beeken R B, Garbe J J, Gillis J M, Petersen N R, Podoll B W and Stoneman M R, 2005. Electrical conductivities of the $\mathrm{Ag}_{6} \mathrm{PS}_{5} \mathrm{X}$ and the $\mathrm{Cu}_{6} \mathrm{PSe}_{5} \mathrm{X}(\mathrm{X}=\mathrm{Br}, \mathrm{I})$ argyrodites. J. Phys. Chem. Solids. 66: 882-886.

10. Pogodin A I, Filep M J, Malakhovska T O, Sabov M Yu, Sidey V I, Kokhan O P and Studenyak I P, 2019. The copper argyrodites $\mathrm{Cu}_{7-n} \mathrm{PS}_{6-\mathrm{n}} \mathrm{Br}_{n}$ : crystal growth, structures and ionic conductivity. Solid State Ionics. 341: 115023.

11. Hanghofer I, Brinek M, Eisbacher S L, Bitschnau B, Volck M, Hennige V, Hanzu I, Rettenwander D and Wilkening H M R, 2019. Substitutional disorder: structure and ion dynamics of the argyrodites $\mathrm{Li}_{6} \mathrm{PS}_{5} \mathrm{Cl}, \mathrm{Li}_{6} \mathrm{PS}_{5} \mathrm{Br}$ and $\mathrm{Li}_{6} \mathrm{PS}_{5} \mathrm{I}$. Phys. Chem. Chem. Phys. 21: 8489-8507.

12. Orliukas A F, Kazakevicius E, Kezionis A, Salkus T, Studenyak I P, Buchuk R Yu, Prits I P and Panko V V, 2009. Preparation, electric conductivity and dielectrical properties of $\mathrm{Cu}_{6} \mathrm{PS}_{5} \mathrm{I}-$ based superionic composites. Solid State Ionics. 180: 183-186.

13. Studenyak I P, Izai V Yu, Studenyak V I, Kovalchuk O V, Kovalchuk T M, Kopčanský P, Timko M, Tomašovičová $\mathrm{N}$, Zavisova $\mathrm{V}$, Miskuf J and Oleinikova I V, 2017. Influence of $\mathrm{Cu}_{6} \mathrm{PS}_{5} \mathrm{I}$ superionic nanoparticles on the dielectric properties of $6 \mathrm{CB}$ liquid crystal. Liq. Cryst. 44: 897-903.

14. Šalkus T, Kazakevičius E, Banys J, Kranjčec M, Chomolyak M M, Neimet $Y u$ Yu and Studenyak I P, 2014. Influence of grain size effect on electrical properties of $\mathrm{Cu}_{6} \mathrm{PS}_{5} \mathrm{I}$ superionic ceramics. Solid State Ionics. 262: 597-600.

15. Studenyak I P, Kranjčec M, Izai V Yu, Chomolyak A A, Vorohta M, Matolin V, Cserhati C and Kökényesi S, 2012. Structural and temperature-related disordering studies of $\mathrm{Cu}_{6} \mathrm{PS}_{5} \mathrm{I}$ amorphous thin films. Thin Solid Films. 520: 1729-1733.

16. Studenyak I P and Kranjčec M. Disordering Effects in Superionic Conductors with Adgyrodite Structure. Uzhhorod: Hoverla (2007).

17. Studenyak I P, Buchuk R Yu, Bendak A V, Yamkovy O O, Kazakevicius E, Salkus T, Kezionis A and Orliukas A F, 2014. Electric conductivity studies of composites based on $\left(\mathrm{Cu}_{1-\mathrm{x}} \mathrm{Ag}_{\mathrm{x}}\right)_{6} \mathrm{PS}_{5} \mathrm{I}$ superionic conductors. SPQEO. 17: 425-428.

18. Azzam R M A and Bashara N M. Ellipsometry and Polarized Light. Amsterdam: NorthHolland Publishing Company (1977).

19. Studenyak I P, Kranjcec M, Kovacs Gy S, Panko V V, Desnica I D, Slivka A G and Guranich $\mathrm{P} \mathrm{P}, 1999$. The effect of temperature and pressure on the optical absorption edge in $\mathrm{Cu}_{6} \mathrm{PS}_{5} \mathrm{X}$ (X= Cl, Br, I) crystals. J. Phys. Chem. Solids. 60: 1897-1904.

20. Wemple S H and Di Domenico M, 1971. Behaviour of the dielectric constant in covalent and ionic materials. Phys. Rev. B. 3: 1338-1352.

21. Tubbs M S, 1970. A spectroscopic interpretation of crystalline ionicity. Phys. Stat. Sol. (b). 41: K61-K64.

22. Urbach F, 1953. The long-wavelength edge of photographic sensitivity and electronic absorption of solids. Phys. Rev. 92: 1324-1326.

23. Kurik M V, 1971. Urbach rule (review). Phys. Stat. Sol. (a) 8: 9-30.

24. Sumi H and Sumi A, 1987. The Urbach-Martiensen rule revisited. J. Phys. Soc. Jap. 56: 2211-2220.

25. Sumi H and Toyozawa Y, 1971. Urbach-Martiensen rule and exciton trapped momentarily by lattice vibrations. J. Phys. Soc. Jap. 31: 342-357.

26. Dow J D and Redfield D, 1972. Toward a unified theory of Urbach's rule and exponential absorption edge. Phys. Rev. B. 5: 594-610.

Ukr. J. Phys. Opt. 2021, Volume 22, Issue 4 
27. Samuel L, Brada Y, Burger A and Roth M, 1987. Urbach rule in mixed single crystals of $\mathrm{Zn}_{\mathrm{x}} \mathrm{Cd}_{1-\mathrm{x}}$ Se. Phys. Rev. B. 36: 1168-1173.

28. Beaudoin M, DeVries A J G, Johnson S R, Laman H and Tiedje T, 1997. Optical absorption edge of semi-insulating GaAs and InP at high temperatures. Appl. Phys. Lett. 70: 3540-3542.

29. Yang Z, Homewood K P, Finney M S, Harry M A and Reeson K J, 1995. Optical absorption study of ion beam synthesized polycrystalline semiconducting $\mathrm{FeSi}_{2}$. J. Appl. Phys. 78: 1958-1963.

30. Cody G D, Tiedje T, Abeles B and Brooks B, Goldstein Y, 1981. Disorder and the opticalabsorption edge of hydrogenated amorphus silicon. Phys. Rev. Lett. 47: 1480-1483.

Studenyak I. P., Pop M. M., Shender I. O., Pogodin A. I. and Kranjcec M. 2021. Temperature behaviour of fundamental absorption edge in superionic $\mathrm{Ag}_{6} \mathrm{PS}_{5} \mathrm{I}$ crystals. Ukr.J.Phys.Opt. 22: $216-224$. doi: $10.3116 / 16091833 / 22 / 4 / 216 / 2021$

Анотація. Монокристали $\mathrm{Ag}_{6} P S_{5}$ I вирощено з розчину-розплаву за методом кристалізації у вертикальній зоні. Дисперсія показника заломлення $\mathrm{Ag}_{6} P S_{5} \mathrm{I}$, виміряна за методом спектральної еліпсометрії, описується відомим співвідношенням Вемпла-ДіДоменіко. Досліджено фундаментальний край поглинання кристалів $\mathrm{Ag}_{6} P S_{5} I$ у діапазоні температур 77-300 К. Температурні залежності оптичної псевдощуілини та енергї Урбаха проаналізовано в рамках моделі Ейнштейна. Визначено параметри електрон-фононної взаємодї, щцо приводить до урбахівської поведінки фундаментального краю поглинання. Досліджено вплив температурних і структурних розупорядкувань на оптичне поглинання 8 $\mathrm{Ag}_{6} P S_{5} I$. 